\title{
O princípio democrático na União Europeia
}

\author{
CARLOS C. PROENÇA' \\ carlosproenca@sapo.pt \\ GALILEU - REVISTA DE DIREITO E ECONOMIA - e-ISSN 2184-1845 \\ Volume XX - $1^{\text {st }}$ July Julho $-31^{\mathrm{TH}}$ December Dezembro $2019 \cdot$ pp. 84-100 \\ DOI: http://doi.org/10.26619/2184-1845.XX.2.5 \\ Submitted on September $18^{\text {th }}, 2019 \cdot$ Accepted on November $15^{\text {th }}, 2019$ \\ Submetido em 18 de Setembro, 2019 . Aceite a 15 de Novembro, 2019
}

RESUMo 1. Introdução; 2. Sentido e alcance do princípio democrático; 3. O princípio democrático enquanto princípio fundamental da União Europeia; 4. A Cidadania Europeia e a consolidação da democracia representativa na União; 5. A democracia positiva e o Parlamento Europeu: procedimento legislativo ordinário e debate de investidura; 6. A democracia negativa e o Parlamento Europeu: o controlo político de outras instituições; 7. O princípio da subsidiariedade e a democracia de proximidade; 8 . O reforço do papel dos Parlamentos nacionais na União Europeia; 9. Cidadania Europeia: o ser ou não ser de uma democracia participativa; 10. Conclusão.

PALAVRaS CHAVE União Europeia, princípio democrático.

ABSTRACT Composed of democratic States, the democratic principle, in order to legitimize public powers, is a fundamental principle of the European Union and its law. Respect for this principle is, on the one hand and first of all, a condition of EU membership, but, on the other hand, it also justified the progressive increase in the powers of the European Parliament (both in political control carried out over other European institutions, as in the adoption of Community legislation), the creation of European citizenship status and the association of national parliaments in the fields of European integration.

KEY WORDS European Union, democratic principle.

1 Professor Universitário na UAL e no ISCAL, e Advogado; Licenciado, Mestre e Doutor em Direito. 


\section{Introdução}

Se em 1947, previamente ao surgimento das Comunidades Europeias², Winston Churchill lançou o gérmen de um princípio democrático de nível europeu, ao propalar "nós não coligamos Estados, nós unimos Homens", ideia retomada por Jean Monnet, em 1952, no discurso de Washington, tal não impediu a ausência de referências ao princípio democrático na versão originária do Tratado da Comunidade Económica Europeia (TCEE)3.

Esta circunstância justificava-se por duas razões. Primeira: o processo de integração europeia apresentou-se, num primeiro momento, com um cariz exclusivamente económico ${ }^{4}$ o que, acompanhado de as competências das Comunidades Europeias serem meramente funcionais, justificava a falta de menções à democracia, bem como a mecanismos de concretização da mesma. Segunda: a tentativa inicial, ainda que não admitida pelo menos de forma expressa, de criação de uma Europa vocacionada para os Estados membros, bem como para as instituições comunitárias, deixando de parte, num primeiro estádio, os cidadãos.

Assim, qualquer tentativa de extração do princípio democrático daquele texto, ou pelo menos do projeto europeu de integração, era rebuscada, porquanto muito embora o Preâmbulo do TCEE referisse, nomeadamente, a determinação dos Estados membros em estabelecer "uma união cada vez mais estreita entre os povos europeus" , tal princípio não merecia qualquer menção expressa no respetivo articulado.

O marco de viragem do ordenamento jurídico comunitário face a este cenário ocorreu com o Tratado da União Europeia (TUE) ${ }^{6}$. Um dos slogans transversal às negociações e à assinatura do mesmo, bem assim aos processos de ratificação e ao início da vigência nos então doze Estados membros da UE, foi o da criação de uma Europa dos Cidadãos. O Tratado de Lisboa7 também conferiu um novo impulso à democracia na União.

Este ensaio incide sobre a evolução do princípio democrático de nível europeu, pilar fundamental em que a UE assenta, descrevendo a sua paulatina evolução e consolidação.

2 Comunidade Europeia do Carvão e do Aço - CECA; a Comunidade Económica Europeia - CEE; e a Comunidade Europeia da Energia Atómica - CEEA.

3 Assinado em Roma, pelos seis Estados membros fundadores, a 25 de março de 1957 e em vigor desde 14 de janeiro de 1958.

4 Com efeito, a designação Comunidade Económica Europeia era eloquente para traduzir um processo de integração inicialmente economicista. Cfr. Luís CRUZ-VILAÇA, A protecção dos direitos dos cidadãos no espaço comunitário, in Valores da Europa - Identidade e Legitimidade, Cascais, 1999, p. 51; João MOTA DE CAMPOS, Manual de Direito Comunitário, Lisboa, 2002, p. 235; Rui MOURA RAMOS, Maastricht e os direitos do cidadão europeu, in Das Comunidades à União Europeia, 2. a ed., Coimbra, 1999, pp. 325 e 326; Maria Luísa DUARTE, A cidadania da União e a responsabilidade dos Estados por violação do Direito Comunitário, Lisboa, 1994, pp. 16 e ss.

5 Tal era e é o $1 .{ }^{\circ}$ considerando, logo a frase de abertura, do Tratado de Roma. Tendo subjacente o princípio democrático, tal excerto foi repetido no artigo $1 .^{\circ}$ do Tratado de Maastricht, assinado volvidos 25 anos.

6 Assinado em Maastricht no dia 7 de fevereiro de 1992, entrou em vigor a 1 de novembro de 1993.

7 Celebrado em 13 de dezembro de 2007, iniciou vigência a 1 de dezembro de 2009. 
Cuidaremos das suas principais consagrações e concretizações, e tentaremos extrair o significado do princípio democrático europeu.

\section{Sentido e alcance do princípio democrático}

A essência do princípio democrático traduz-se em duas formulações que, podendo à partida parecer contraditórias, não são. A fórmula clássica, de Abram Lincoln, é positiva ${ }^{8}$ e propõe a democracia como o "governo do povo, pelo povo e para o povo" 9 . A fórmula provocatória, de Karl Popper, é negativa ${ }^{10}$ e propala que "a democracia nunca foi a soberania do povo, não o pode ser, não o deve ser".

Em ambas o princípio democrático aponta, tanto no contexto nacional como no quadro europeu, para a legitimação do poder político. Quer dizer: com ele visa-se responder à seguinte questão: porque há governantes e governados? A resposta aponta - e nisso consiste a verdadeira essência do princípio democrático - para a legitimação popular exercida através (i) do voto (universal, secreto, periódico e igual) para a eleição dos órgãos representativos e (ii) do referendo ${ }^{11}$ sempre que os cidadãos sejam chamados a pronunciar-se diretamente sobre questões de relevante interesse. Isto é, se entendermos o poder como domínio político (ou um domínio legitimado de homens sobre homens) ou como soberania (no sentido da competência para a formação da vontade política de um Estado), o titular desse poder é o povo, daqui se extraindo que o princípio democrático é concretizado pela soberania popular. Daí que aquelas formulações de democracia não sejam contraditórias: ambas defendem que a democracia repousa na legitimação popular já que inexistem outras formas de legitimação, divinas ou partidárias, do poder político. Segundo o princípio democrático, somente a legitimação do povo autoriza o exercício do poder político, pelo que a democracia é, com efeito, o poder e o governo do povo.

Enquanto governo do povo, a democracia manifesta-se através de duas formas.

A forma representativa, que exige órgãos representativos, eleições periódicas, pluralismo partidário e separação de poderes. Ou seja, num sistema político baseado no poder do povo, mas onde nem todos os cidadãos se encontram dotados das características necessárias para saberem dar resposta às aspirações da comunidade, há necessidade de proceder à esco-

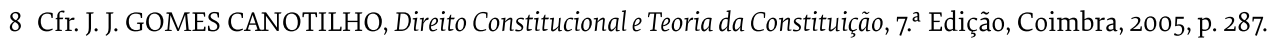

9 Cfr. Ana Maria GUERRA MARTINS, Curso de Direito Constitucional da União Europeia, Coimbra, 2004, p. 213; Leonardo COIMBRA, Dispersos V. Filosofia e Política, Lisboa/São Paulo, 1994, p. 219.

10 Cfr. J. J. GOMES CANOTILHO, Direito..., cit., p. 291.

11 Mecanismo consolidado nos Estados membros e de que foi exemplo a ratificação, pela via referendaria, prevista em vários daqueles Estados, do abandonado Tratado que pretendeu instituir uma Constituição para a Europa. 
lha ou à seleção das pessoas dotadas dessas qualidades, traduzindo-se numa perspetiva de output centrada na representação.

E a forma participativa, que reclama processos que confiram aos cidadãos reais possibilidades de apreender a democracia, participar nos processos decisórios, controlar criticamente divergências de entendimentos ${ }^{12}$. Esta forma preconiza que todos os cidadãos devem participar nos domínios políticos, influenciando-os ou contribuindo para influenciá-los, dando prevalência a uma perspetiva de input, que significa participação e intervenção política direta do povo nos assuntos da polis.

Os sistemas jurídico-constitucionais dos Estados membros têm dado prevalência à visão de output, concentrada na democracia representativa ou na representação democrática, a qual, naturalmente, se alastrou à UE.

Paralelamente àquelas formas, duas conceções correlativas consubstanciam sequelas da prevalência de cada uma daquelas manifestações do princípio sub judice. Na democracia participativa, assente em instrumentos de participação ou em inputs políticos democráticos, predomina uma conceção de democracia positiva, a qual defende a legitimação dos governantes através de eleições, conferidoras de um título legitimador do poder político atribuído aos governantes. Na democracia representativa, baseada em mecanismos que procuram conferir seletividade, representação, racionalidade ao princípio democrático, e orientada por expedientes de outputs, prevalece uma conceção de democracia negativa, que defende a preferência por mecanismos de controlo, fiscalização e revogação dos titulares de cargos políticos. Ambas se afiguram importantes, pois se a montante há necessidade de legitimar o poder político em que investimos os governantes, a jusante exige-se o controlo da sua atuação e do seu desempenho.

\section{O princípio democrático enquanto princípio fundamental da União Europeia}

A democracia apresenta-se um princípio estruturante da UE e um princípio comum aos Estados membros, ou seja, a UE é uma União de Estados democráticos. A principal referência expressa e direta à democracia consta do artigo $2 .^{\circ}$ do TUE, onde se estabelece que a União se funda em vários princípios, entre eles o democrático, os quais são partilhados por todos os Estados membros. Retoma-se no articulado do Tratado um princípio afirmado, antes de mais, no respetivo Preâmbulo, já que os seus considerandos $2 .^{\circ}$ e $4 .^{\circ}$ afirmam o

12 Cfr. J. J. GOMES CANOTILHO, Direito..., cit., p. 288, a propósito da lição sobre o princípio democrático-normativo como princípio complexo. 
apego dos Estados membros a vários princípios nos quais a União se inspira, um dos quais o princípio democrático. A democracia surge, pois, como princípio fundamental da UE ${ }^{13}$, que, por isso, não comporta a suscetibilidade de derrogação na ordem jurídica interna dos Estados membros ${ }^{14}$.

Se, por um lado, a referida norma determina que a UE se funda na democracia, por outro lado, o considerando $4 .^{\circ}$ do TUE plasma o apego dos Estados membros ao princípio democrático. Estas diferenças traduzem um significado político que assenta na natureza da UE como organização internacional sui generis (e não como um Estado, nomeadamente federal); também não existe um povo europeu, tal como inexiste um governo europeu. Logo, diferentemente do que sucede no âmbito interno (isto é, no quadro dos Estados-nação), no atual estado do processo europeu de integração é prematuro falar-se numa soberania popular europeia. Sem se ignorar a inserção do princípio democrático nos princípios constitucionais da UE, o mesmo apresenta um alcance distinto daquele que lhe é conferido no plano nacional.

Esta ilação extrai-se da decisão de 12 de outubro de 1993, conhecida por acórdão MAASTRICHT, confirmada pelo aresto de 30 de junho de 2009, designado de acórdão LISBOA, ambos proferidos pelo Tribunal Constitucional Federal Alemão (adiante BVerfG), no quadro dos processos de ratificação dos Tratados de Maastricht e de Lisboa, e refletindo o seu ativismo judiciário na posição que marcou a propósito da natureza do processo de integração europeu.

Em especial, o BVerfG recusou a existência de qualquer poder constituinte europeu no âmbito da UE, entendendo tratar-se antes de um poder derivado, já que são os Estados, através dos seus órgãos de soberania, que decidem a adesão àquelas, conservando-se como os "donos do Tratado". Considerou ainda que a integração europeia não poderia levar ao esvaziamento dos poderes do Parlamento Federal e que a faculdade de a Alemanha participar numa comunidade de Estados está condicionada, devendo ser sempre garantida e legitimada pelo povo alemão; o papel dos Parlamentos nacionais será sempre decisivo na transferência de competências para as entidades supranacionais, tendo a extensão das atribuições europeias limites que resultam de não ser possível esvaziar por completo as tarefas nacionais. Dois aspetos particularmente interessantes destes acórdãos foram, por um lado, a negação do caráter federal à UE, entendendo o Tribunal que esta mais não é do que uma

13 Cfr. FAUSTO DE QUADROS, Direito da União Europeia, 3. ${ }^{\text {a }}$ Ed, Coimbra, 2013, pp. 136 e ss; João MOTA DE CAMPOS, Manual..., cit., pp. 259 e ss.

14 Tal afastamento seria "um atentado inaceitável contra o espírito da União Europeia, na medida em que poria irremediavelmente em causa a homogeneidade e a coesão do bloco de países que dela fazem parte", ensina João MOTA DE CAMPOS, Manual..., cit., p. 259. 
associação de Estados (Staatenverbund) evitando falar em União e até em Comunidade; por outro lado, a consideração de que o processo de integração não é irreversível, podendo a Alemanha sair da UE quando o desejar, estando as futuras transferências de competências e atribuições dependentes da autorização das entidades nacionais.

Estas decisões, no fundo, confirmaram que a UE não é um Estado ${ }^{15}$, já que para o ser teria que deter a competência geral ou a "competência das competências" (Kompetenz-Kompetenz), a qual permanece nos Estados. A União nunca esteve dotada do poder de auto-organização pelo qual elaboraria a sua Constituição, definiria as respetivas atribuições, criaria os seus órgãos e fixar-lhes-ia competência, assim faltando-lhe a primeira característica de um Estado ${ }^{16}$. Tal como são os Estados que detêm, entre outros, o poder de rever os Tratados.

\section{A Cidadania Europeia e a consolidação da democracia representativa na União}

Com a entrada em vigor do Tratado de Maastricht os Estados membros das Comunidades instituíram a UE, a qual, até à entrada em vigor do Tratado de Lisboa, assentou numa peculiar estrutura de três pilares, cada um com os seus objetivos e instrumentos próprios ${ }^{17}$.

O TUE também criou a Cidadania Europeia ${ }^{18}$. Em concretização do (novo) objetivo de reforço da defesa dos direitos e dos interesses dos nacionais dos Estados membros, então previsto no $3 .^{\circ}$ travessão do artigo $2 .^{\circ}$ do TUE, consagrou-se pela primeira vez ao nível do direito primário um estatuto comum aos nacionais dos Estados membros lapidarmente denominado de Cidadania da União, traduzindo um assinalável reforço da democracia na UE ${ }^{19}$. Tal Tratado alterou

15 Vide FAUSTO DE QUADROS, Direito..., cit., pp. 134 e ss. e 238 e ss.

16 Cfr. FAUSTO DE QUADROS, Direito..., cit., p. 139; Maria Luísa DUARTE, A teoria dos poderes implícitos e a delimitação de competências entre a União Europeia e os Estados membros, Lisboa, 1997, pp. 220, 221 e 484; J. J. GOMES CANOTILHO, Direito..., cit., pp. 58 e 70; Jorge MIRANDA, O Direito Constitucional Português da Integração Europeia. Alguns aspectos, in AAVV, Nos 25 anos da Constituição da República Portuguesa de 1976. Evolução constitucional e perspectivas futuras, Lisboa, 2001, pp. 16 a 26.

17 Com efeito, a União fundava-se nas três Comunidades Europeias, que constituíam o pilar de integração (ou primeiro pilar), complementadas pelos pilares intergovernamentais: a PESC (segundo pilar) e a CJAI (terceiro pilar), esta posteriormente reduzida à Cooperação Policial e Judiciária em Matéria Penal em virtude da comunitarização parcial do terceiro pilar operada pelo Tratado de Amesterdão, porquanto as matérias relativas a vistos, asilo e imigração e outras políticas relativas à livre circulação de pessoas passaram a relevar ao nível do primeiro pilar e ao método da integração supranacional. O Tratado de Lisboa pôs fim a essa estrutura, pelo menos do ponto de vista formal. Cfr. FAUSTO DE QUADROS, Direito..., cit., p. 157.

18 Uma vez que as atribuições da anterior CEE, além de económicas, eram também de outras naturezas, como sociais, culturais e políticas, o TUE alterou ainda designação daquela para CE, a que não foi alheio o instituto da Cidadania da União.

19 Cfr. FAUSTO DE QUADROS, Direito..., cit., p. 158; João MOTA DE CAMPOS, Manual..., cit., pp. 239 e ss.; Rui MOURA RAMOS, op. cit., pp. 327, 328, e 346. Falando no instituto da Cidadania da União enquanto mecanismo 
qualitativamente a liberdade de circulação de pessoas e transpôs a ótica meramente económica em que assentava o mercado comum tal como inicialmente concebido pelo Tratado de Roma ${ }^{20}$. No campo da Cidadania da União, o atual Tratado sobre o Funcionamento da UE (TFUE; ex-Tratado da Comunidade Europeia - TCE) concede aos nacionais dos Estados membros o direito de circulação e permanência livre no território daqueles enquanto espaço sem fronteiras internas, independentemente do exercício de qualquer atividade profissional'1.

A nova configuração da liberdade de circulação de pessoas, emancipada de uma ótica integrativa de raiz economicista, dificilmente poderia deixar de ser acompanhada da atribuição aos cidadãos da União de direitos, não apenas de caráter económico e social, mas também político, que lhes permitissem sentir-se como participantes de pleno direito de um processo de integração evolutivo ${ }^{22}$. Daí o estatuto de cidadania da União atribuir aos cidadãos europeus residentes em Estados membros que não sejam os das suas nacionalidades, em decorrência do princípio da não discriminação em razão da nacionalidade, dois direitos públicos de participação política eleitoral: os de elegerem e serem eleitos nas eleições para o Parlamento Europeu (PE) e nas eleições municipais dos Estados membros de residência nas mesmas condições que os nacionais destes Estados ${ }^{23}$. Tais prerrogativas contribuíram para a consolidação do princípio democrático na UE, porquanto, tratando-se de direitos de participação política, reforçaram o sentimento de identificação dos cidadãos europeus com o Estado membro onde residem (por via da participação eleitoral autárquica)

concretizador de um sentido restrito de cidadania, ao qual se contrapõe uma aceção ampla de cidadania europeia, composta não apenas pelos direitos civis e políticos enunciados nos artigos $20 .^{\circ}$ a $24 .^{\circ}$ do TFUE, mas por todos os direitos de que são titulares os nacionais dos Estados membros da UE e cuja fonte é tanto o direito originário como o derivado, ver Marcelo REBELO DE SOUSA, A cidadania Europeia - Nível de concretização dos direitos, possibilidade de alargamento e suas implicações, in Em torno da revisão do Tratado da União Europeia, Coimbra, 1997, pp. 119, 120, e 127 e ss.

20 Merecem referência as conclusões que o Advogado-geral JACOBS teceu no caso BICKEL E FRANZ, que originou o acórdão do Tribunal de Justiça de 24 de novembro de 1998, processo C-274/96, Col. 1998, pp. 7645 e ss: "a noção de cidadania da União implica uma comunidade de direitos e obrigações que unem os cidadãos da União por um vínculo comum que transcende a nacionalidade de um Estado membro. A introdução deste conceito foi largamente inspirada pela preocupação de aproximar a União dos seus cidadãos e de exprimir a sua natureza como algo diverso de uma União puramente económica. Esse intento encontra-se reflectido no abandono da expressão «económica» na denominação da Comunidade e pela progressiva introdução, no Tratado CE, de um amplo conjunto de actividades e de políticas que extravasam do âmbito económico".

21 Cfr. Ana Maria GUERRA MARTINS, Curso..., cit., p. 189.

22 Cfr. João MOTA DE CAMPOS, Manual..., cit., p. 236. Assiste-se aqui àquilo que Boaventura SOUSA SANTOS chamaria de "paradigma emergente", enquanto uma ampla expansão e dispersão do direito democrático e da cidadania. Ver Crítica da razão indolente. Contra o desperdicio da experiencia, Porto, 2002, p. 315.

23 Também aqui surge plasmado o princípio do tratamento nacional. Neste sentido Miguel GORJÃO-HENRIQUES,

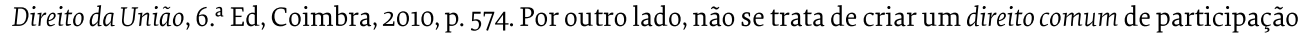
política com o mesmo conteúdo no território dos Estados, mas sim de assimilar o cidadão residente num Estado membro aos nacionais respetivos. Assim Rui MOURA RAMOS, op. cit., p. 351. 
bem como com a UE (através da participação eleitoral para o PE). Da alínea b) do n. ${ }^{\circ} 2$ do artigo $20{ }^{\circ}$ do TFUE decorre que o critério de participação naqueles escrutínios deixou de ser exclusivamente o da nacionalidade, para ser também o da residência ${ }^{24}$. Destaque merece ainda a equiparação, para este efeito, entre as capacidades eleitorais ativa (direito de eleger) e passiva (direito de ser eleito). Ambos os direitos inserem-se na dimensão representativa do princípio democrático, já que aquelas prerrogativas acolhem recortes dos mais importantes postulados da teoria democrática representativa (órgãos representativos, eleições periódicas e pluralismo partidário). Não obstante, os Estados membros também tiveram em conta a necessidade de conferir eficiência, seletividade e racionalidade ao referido princípio, a que não foi imune uma orientação de output do mesmo.

A nova configuração da forma de participação dos cidadãos da União nas eleições para o PE constitui um assinalável reforço da legitimidade democrática desta instituição. A novidade não reside na eleição por sufrágio direto e universal ${ }^{25}$, mas sim na aquisição de ambas as capacidades eleitorais pelo critério do Estado membro de residência, representando um plus para a dimensão representativa pluralista do princípio democrático na UE. Este direito implica, maxime no que tange à capacidade eleitoral passiva, a participação direta dos cidadãos europeus nas prerrogativas do poder político do Estado de residência através da instituição europeia (a única dotada de legitimidade democrática direta ${ }^{26}$ ) que participa nos procedimentos decisórios de aprovação de legislação comunitária (v.g. regulamentos e diretivas).

Os direitos de eleger e de ser eleito nas eleições locais do Estado de residência espelham que a participação nos assuntos políticos europeus não se cinge à União, considerada distintamente dos Estados que a compõem ${ }^{27}$. Tratando-se da participação nas eleições autárquicas, está em causa a escolha dos titulares dos órgãos do poder local dos Estados

24 Como observa Rui MOURA RAMOS, op. cit., p. 350, esta norma veio "integrar os cidadãos da União residentes num dado Estado membro no respectivo povo, independentemente da posse da nacionalidade respectiva, ao menos no que releva para os efeitos da eleição do Parlamento Europeu".

25 Nem sempre assim aconteceu. Desde a criação das Comunidades e durante mais de 20 anos, os membros do $\mathrm{PE}$, então delegados (e não deputados), eram nomeados pelos Parlamentos nacionais e escolhidos de entre os seus membros (e não eleitos pelos povos dos Estados). Remonta a 1975 a primeira concretização relevante, expressa num relatório da Comissão, do ensejo de o PE ser composto por representantes dos povos eleitos por sufrágio universal, a qual mereceu a concordância desta instituição. Em 20 de setembro de 1976 o Conselho aprovou os textos relativos à eleição dos membros do $\mathrm{PE}$ por sufrágio universal e secreto, os quais foram objeto de ratificação, pelos Estados membros, em conformidade com as respetivas normas constitucionais. A primeira eleição dos membros do PE ocorreu, simultaneamente em toda a Comunidade, em 10 de junho de 1979, o que contribuiu não só para o reforço da legitimidade do $P E$, na medida em que a mesma passou a ser direta, como também para se ascender à Europa dos povos. Cfr. Giancarlo OLMI, Introdução, in Trinta anos de Direito Comunitário, Bruxelas, 1981, pp. 11 e 12; Guy SCHRANS, A Comunidade e as suas instituições, in Trinta anos..., cit., pp. 28 a 30.

26 Na síntese de RUI MOURA RAMOS, op. cit., p. 333, o PE trata-se de uma instituição que deve a sua existência a uma manifestação da vontade dos cidadãos europeus.

27 Cfr. Rui MOURA RAMOS, op. cit., p. 350. 
membros e nelas podem participar os cidadãos europeus que aí residam. Em Portugal, a Constituição prevê a capacidade eleitoral dos estrangeiros residentes em Portugal para a eleição dos titulares de órgãos autárquicos desde a revisão constitucional de 1989, tendo a revisão de 1992 esclarecido que tal capacidade eleitoral é ativa e passiva ${ }^{28}$.

\section{A democracia positiva e o Parlamento Europeu: procedimento legislativo ordinário e debate de investidura}

A conceção positiva de democracia assume maior importância se tivermos presente que o PE tem aumentado os seus poderes consideravelmente ao longo dos mais de cinquenta anos do processo europeu de integração.

Em matéria de procedimentos decisórios de adoção dos atos europeus (entre os quais, legislativos) de direito derivado previstos no Tratado de Roma, evoluiu-se de um processo em que o PE era apenas consultado para um processo de cooperação e mais tarde de codecisão, com o Tratado de Lisboa renomeado de processo legislativo ordinário e elevado a procedimento decisório-regra ${ }^{29}$ na adoção de atos pelas instituições europeias ${ }^{30}$. Se nos dois primeiros o Parlamento era apenas ouvido, não conseguindo impedir o Conselho de adotar propostas ${ }^{31}$, no atual quadro o $\mathrm{PE}$ "logrou, finalmente, o estatuto há muito tempo reivindicado de órgão decisor em domínios fundamentais da regulação comunitária"32. Com efeito, neste procedimento o poder decisório é repartido entre o Parlamento e o Conselho, o que obriga a uma aproximação e à obtenção de consensos para que as propostas se concretizem em atos. Nesta evolução é visível o aumento da legitimidade democrática na tomada de decisões, o que incrementa a importância da eleição direta do $\mathrm{PE}$, bem como da extensão da capacidade eleitoral aos cidadãos europeus residentes num Estado membro do qual não são nacionais, vislumbrando-se um relevante passo no processo europeu de integração no que concerne à consolidação do princípio democrático.

O papel do PE na investidura dos membros da Comissão Europeia, incluindo o seu Presidente, também releva na efetivação democrática na União e, nele, também se vislum-

28 O mesmo acontecia na Dinamarca, na França e no Luxemburgo, países nos quais o direito interno já reconhecia a não nacionais (não necessariamente com a nacionalidade de outro Estado membro da UE, note-se) capacidade eleitoral ativa e passiva nas eleições autárquicas.

29 Cfr. artigos $289 .^{\circ}$ e $294 .^{\circ}$ do TFUE.

30 Sobre os procedimentos decisórios ver Maria Luísa DUARTE, Direito da União Europeia e das Comunidades Europeias, Vol. I, Tomo I, Lisboa, 2001, pp. 223 e ss.

31 De facto, no processo de consulta o PE limita-se a emitir um parecer que não é vinculativo; e no procedimento de cooperação, o "melhor" a que o PE poderia aspirar era, mediante rejeição da posição comum do Conselho, forçar esta instituição a deliberar por unanimidade, caso a mesma pretendesse a aprovação do ato.

32 Assim Maria Luísa DUARTE, Direito..., cit., p. 242. 
bra um traço da conceção positiva de democracia. Obtido o consenso no Conselho Europeu relativamente à personalidade a nomear Presidente da Comissão, é imprescindível que tal nomeação seja aprovada, mediante sufrágio, pelo PE. No debate de investidura que antecede a votação, a personalidade indicada deve responder satisfatoriamente às perguntas colocadas pelos deputados europeus e cujo objeto se prende com as orientações e o rumo político pretendido caso seja designada. Eleita a personalidade, segue-se a escolha dos restantes comissários (entre eles o Alto Representante da União para os Negócios Estrangeiros e Política de Segurança), onde participam o Conselho (ou novamente o Conselho Europeu no caso do Alto Representante) e o recém-eleito Presidente da Comissão. A lista dos futuros comissários é submetida a nova aprovação, agora colegial ${ }^{33}$, designada de voto de aprovação parlamentar, após o que se segue a nomeação definitiva do colégio de comissários pelo Conselho Europeu. Através destas competências, o PE contribui para a legitimidade democrática, ainda que indireta, da Comissão.

\section{A democracia negativa e o Parlamento Europeu: o controlo político de outras instituições}

A conceção negativa de democracia também está presente na UE, nomeadamente nos mecanismos de que o PE dispõe para controlar politicamente outras instituições.

A moção de censura, prevista nos artigos $17 .^{\circ}$, n. ${ }^{\circ}$ 8, do TUE e $234 .{ }^{\circ}$ do TFUE (e $119 .{ }^{\circ}$ do Regimento Interno do PE), ocupa um papel primordial nos instrumentos de controlo, fiscalização e de revogação. Caso seja adotada por maioria de dois terços dos votos expressos desde que represente a maioria dos 751 membros que compõem o Parlamento, a Comissão é forçada a cessar funções coletivamente.

Importantes afiguram-se, também, o expediente das questões orais e escritas e o mecanismo das comissões de inquérito. Nos termos do artigo $230{ }^{\circ}$ do TFUE (conjugado com os artigos $128 .^{\circ}$ e seguintes do Regimento do PE), a Comissão e o Conselho devem responder às questões colocadas pelo $\mathrm{PE}$ ou pelos seus deputados. $\mathrm{O}$ artigo $226 .^{\circ}$ do TFUE (e $198 .^{\circ}$ do Regimento) possibilita ao PE, a pedido de um quarto dos seus membros, determinar a constituição de comissões parlamentares de inquérito para analisar infrações ou situações de má administração na aplicação do direito da UE, contando que os factos

33 Afigura-se importante salientar que desde janeiro de 1995, por altura da aprovação da Comissão liderada por Jacques Santer, o PE, previamente ao voto de aprovação parlamentar que se dirige ao colégio de comissários, submete a audições individuais cada comissário indigitado, mecanismo prévio de controlo inspirado no sistema de «hearings» do Senado norte-americano e semelhante ao que ocorre previamente com o Presidente da Comissão. 
não sejam objeto de um processo judicial, resultantes de atos das instituições, dos órgãos ou organismos da União, da administração pública de um Estado membro ou de pessoas incumbidas aplicação pelo direito da UE.

Os direitos de petição ao PE e de queixa ao Provedor de Justiça Europeu, direitos públicos de participação política (e cívica) não eleitoral decorrentes da cidadania da União, também contribuem para a fiscalização dos titulares de cargos políticos nas instituiçõos europeias. Se os restantes direitos que integram o estatuto de cidadania da União têm um conteúdo substantivo, nestes dois destaca-se a natureza adjetiva, instrumental ou procedimental ${ }^{34}$, porquanto se trata de mecanismos de garantia graciosa ${ }^{35}$. Previstos na alínea d) do $\mathrm{n} .{ }^{0} 2$ do artigo $20 .^{\circ}$ e nos artigos $227 .^{\circ}$ e $228 .^{\circ}$ do TFUE, trata-se de direitos onde, embora prevaleça a ótica de output-representação $0^{36}$, se vislumbra um resquício da visão de input-participação, pois, não obstante possam destinar-se também ao controlo, quiçá à revogação do mandato de algum titular de um cargo político, os mesmos podem ser despoletados pelos cidadãos europeus, embora não exclusivamente pois também radicam em qualquer outra pessoa singular ou coletiva com residência ou sede estatutária num Estado membro ${ }^{37}$.

\section{O princípio da subsidiariedade e a democracia de proximidade}

Genericamente, o princípio da subsidiariedade radica na repartição de atribuições entre várias comunidades e visa a descentralização na comunidade menor das funções da comunidade maior ${ }^{38}$. Esta só poderá prosseguir atribuições daquela se a mesma se mostrar incapaz de as realizar melhor. As comunidades encontram-se, assim, organizadas de forma escalonada ou piramidal, encontrando-se o Estado no topo ${ }^{39}$. Apesar da sua inspiração federal $^{40}$, o princípio da subsidiariedade não é apanágio dos Estados federais, como bem se demonstra, entre nós, no artigo $6 .^{\circ}, \mathrm{n} .{ }^{\circ} 1$, da CRP. Classicamente, o princípio da subsidia-

34 Assim FAUSTO DE QUADROS, Direito..., cit., p. 164; também Rui MOURA RAMOS, op. cit., p. 340.

35 Os quais acrescem aos mecanismos do contencioso comunitário há muito existentes.

36 Miguel GORJÃO-HENRIQUES, op. cit., p. 576, apelida-os de direitos de "controlo democrático" dos órgãos comunitários.

37 Trata-se de direitos que ultrapassam a circunscrição decorrente do estatuto de cidadania, o que é compreensível se considerarmos que o que releva aqui, mais do que o estatuto de cidadão, é a qualidade de administrado. Por outro lado, com Maria Luísa DUARTE, Direito..., cit., p. 197, os princípios da legalidade europeia e da transparência também subjazem a este alargamento da legitimidade.

38 Cfr. FAUSTO DE QUADROS, O princípio da subsidiariedade no Direito Comunitário após o Tratado da União Europeia, Coimbra, 1995, pp. 17 e 18; Ana Maria GUERRA MARTINS, O Tratado da União Europeia. Contributo para a sua compreensão, Lisboa, 1993, p. 36.

39 Para Jacques DELORS, a subsidiariedade manifesta-se de duas formas distintas: por um lado, na delimitação da esfera de atuação do Estado, entendido na sua aceção lata; por outro, na repartição de atribuições entre os diferentes níveis do poder político. Cfr. Le nouveau concert européen, Paris, 1992, p. 163.

40 Cfr. João MOTA DE CAMPOS, Manual..., cit., p. 269. 
riedade recusa o monopólio da Administração na prossecução do interesse público ${ }^{41}$, preferindo a prossecução deste pelos corpos sociais que se situam entre o Estado e o cidadão, o que concretiza um princípio de participação e constitui uma manifestação da democracia $^{42}$. Os termos descentralizar e movimento ascendente fazem parte da sua essência ${ }^{43}$. A intervenção da comunidade maior justifica-se pela (i) necessidade e pela (ii) melhor eficácia na prossecução da atribuição em causa ${ }^{44}$, as quais constituem os requisitos concretizadores da aplicação do princípio ${ }^{45}$.

O Tratado de Maastricht institucionalizou o princípio da subsidiariedade no direito comunitário $0^{46}$ mediante a cláusula geral inserida no $2 .^{\circ}$ parágrafo do artigo $3 .^{\circ}$-B (renumerado de artigo $5 .{ }^{\circ}$ com o Tratado de Amesterdão) do TCE ${ }^{47}$, a qual, confirmando os dois requisitos de que depende o respeito do referido princípio ${ }^{48}$, pressupunha a relação entre dois níveis distintos de comunidades humanas e visava a repartição das atribuições entre os Estados membros e a CE, ou, mais rigorosamente, a regulação do exercício daquelas atribuições. Tal não significava, porém, que a subsidiariedade só operasse no âmbito de atuação da aludida Comunidade ${ }^{49}$, sendo os seus contornos delimitados pelo quadro global de atividade

41 Jacques DELORS, op. cit., p. 165, destaca que a subsidiariedade não se traduz apenas num limite à intervenção da entidade superior, mas também numa obrigação de esta agir com respeito pelos níveis decisórios inferiores.

42 FAUSTO DE QUADROS, O princípio..., cit., p. 18.

43 Todavia, refira-se que há outra corrente doutrinária (entre nós, João MOTA DE CAMPOS, Manual..., cit., pp. 269 e 270) que defende que o princípio da subsidiariedade permite o contrário, ou seja, a centralização, operando como um movimento descendente, uma vez que os Estados membros devem transferir para a UE todas as tarefas que esta esteja em condições de realizar melhor do que os Estados isoladamente. Cfr. FAUSTO DE QUADROS, O princípio..., cit., p. 32; Ana Maria GUERRA MARTINS, O Tratado..., cit., p. 40.

44 A este propósito Ana Maria GUERRA MARTINS, O Tratado..., cit., p. 44, propõe o recurso a dois testes: o teste da eficácia comparativa (pelo qual se averigua se existem meios disponíveis por parte dos Estados para atingir os objetivos da ação prevista) e o teste do valor acrescentado (mediante o qual se avalia a eficácia da ação comunitária, a dimensão, os problemas transfronteiriços ou os custos da inação).

45 Ver Jacques DELORS, op. cit., p. 165.

46 Apesar de ele já se vislumbrar no horizonte da integração europeia antes deste marco histórico, foram, no entanto, os trabalhos preparatórios do TUE que propuseram a elevação da subsidiariedade a princípio fundamental da integração europeia, sobretudo após o Relatório Giscard d'Estaing, aprovado por Resolução do PE de 12 de junho de 1990, e depois do Conselho Europeu de 14 e 15 de dezembro de 1990 que, convocando duas Conferências Intergovernamentais (uma sobre a União Política e a outra sobre a União Económica e Monetária), sublinhou o significado que deveria ser conferido ao princípio da subsidiariedade nos trabalhos daquelas conferências.

47 A cláusula geral não esgotava, contudo, a institucionalização do princípio da subsidiariedade nos Tratados, uma vez que ela era completada por outras concretizações decorrentes do mesmo princípio, umas constantes do Preâmbulo do TUE, outras presentes em alguns artigos do mesmo Tratado (por exemplo, no artigo B), outras visíveis em preceitos do TCE. Cfr. Ana Maria GUERRA MARTINS, O Tratado..., cit., p. 41; FAUSTO DE QUADROS, O principio..., cit., pp. 34 a 36.

48 Os quais também constavam do $5 .^{\circ}$ parágrafo do primeiro Protocolo relativo à aplicação dos princípios da subsidiariedade e da proporcionalidade, inicialmente anexo ao TCE e adotado pela CIG que aprovou o Tratado de Amesterdão.

49 Cfr. FAUSTO DE QUADROS, O principio..., cit., p. 33; Direito..., cit., p. 402; Ana Maria GUERRA MARTINS, O Tratado..., cit., p. 41; Miguel GORJÃO-HENRIQUES, op. cit., p. 384. 
da UE, constituindo, portanto, um principio fundamental de toda a União e não apenas da $C E^{50}$, o que era confirmado pelo último parágrafo do artigo $2 .{ }^{\circ}$ do TUE, que vinculava a União ao respeito pelo princípio da subsidiariedade na prossecução dos seus objetivos. Precisamente por isso, o Tratado de Lisboa transferiu a cláusula geral de subsidiariedade para o artigo $5 .^{\circ}\left(\right.$ n. $\left.{ }^{\circ} 2\right)$ do TUE.

A Conferência Intergovernamental (CIG) que aprovou o Tratado de Lisboa também estabeleceu um novo Protocolo anexo ao TUE, ao TFUE e ao TCEEA relativo aos princípios da subsidiariedade e da proporcionalidade, o qual obriga as instituições europeias ao respeito contínuo de tais princípios, maxime no âmbito dos procedimentos de aprovação de atos legislativos da União, fundamentando em que medida os inerentes projetos respeitam ambos os princípios, e associa os Parlamentos nacionais à fiscalização política do respeito pelos mesmos ${ }^{51}$, em claro reforço do princípio democrático na UE.

Quanto à sua dinâmica, naturalmente o campo de atuação do princípio da subsidiariedade prende-se com os domínios que não sejam das atribuições europeias exclusivas, porquanto nestas $^{52}$ a União, atuando mediante políticas comuns, já se substituiu aos Estados; portanto, o princípio da subsidiariedade apenas opera no âmbito de atribuições concorrentes ou paralelas entre a UE e os Estados membros, isto é, que possam ser prosseguidas por ambos, priorizando ou preferindo a intervenção dos Estados ${ }^{53}$. A União só deverá substituir-se aos Estados membros quando a ação prevista tenha dimensão e eficácia a uma escala tendencialmente europeia ou, pelo menos, transnacional; ou seja, a ação empreendida a nível nacional (central, regional ou local) ou, pela negativa, a ausência de uma ação a nível europeu, é contrária às exigências do TFUE ${ }^{54}$ ou lesa significativamente os interesses dos Estados; trata-se, no entanto, de um problema cuja resposta será casuística. Para se reduzir a elevada dose de discricionariedade que o princípio da subsidiariedade confere às instituições europeias exige-se que na fundamentação dos atos, inclusivamente nos respetivos

50 Cfr. FAUSTO DE QUADROS, O princípio..., cit., p. 33.

51 Tal controlo tem lugar a montante, pelo que o seu principal objetivo reside na prevenção de violações ao princípio. O artigo $6 .^{\circ}$ do novo Protocolo atribui aos Parlamentos nacionais o poder de intervirem no decurso do processo legislativo quando entenderem que as propostas de atos não respeitam o princípio da subsidiariedade. Para o efeito, qualquer Parlamento nacional pode, no prazo de oito semanas a contar da data de envio de um projeto de ato legislativo, dirigir aos Presidentes do Conselho, da Comissão e do PE um parecer fundamentado no qual exponha os motivos pelos quais considera que o projeto desrespeita o princípio da subsidiariedade. É o designado mecanismo de alerta rápido.

52 Política comercial comum, política agrícola comum, política comum de pescas, etc.

53 Cfr. Vlad CONSTANTINESCO, Le principe de subsidiarité: un passage obligé vers l'Union Européenne, in Mélanges en hommage à Jean Boulouis, Paris, 1991 pp. 44 e 45; FAUSTO DE QUADROS, Direito..., cit., p. 140; O principio ..., cit., pp. 43 e 44.

54 Provocando, por exemplo, distorções na concorrência ou restrições às trocas comerciais. 
projetos ou propostas, se motive ou justifique a intervenção da UE em detrimento da atuação dos Estados membros.

Por outro lado, em matéria de atos de direito derivado previstos no artigo $288 .^{\circ}$ do TFUE, verifica-se uma preferência das diretivas sobre os regulamentos, na medida em que as primeiras consubstanciam atos normativos que melhor respeitam o princípio da subsidiariedade ${ }^{55}$.

A subsidiariedade foi o preço pago pelos Estados mais integracionistas pelo alargamento dos objetivos da UE e dos meios necessários à sua realização ${ }^{56}$. Como ensina J. J. GOMES CANOTILHO, por de trás do mencionado princípio está "a ideia de freio e balanço relativamente a um crescente «centralismo europeu»; a ideia de «regionalizar» mais fortemente os processos de decisão comunitária"57. Contudo, a principal apreensão subjacente ao princípio da subsidiariedade encontra-se intimamente ligada com o princípio democrático: nele avulta a aproximação do poder dos cidadãos e a necessidade de encontrar decisões mais próximas deles. Pretende-se, em suma, alcançar uma democracia da proximidade ${ }^{58}$, propalada na parte final do $2 .^{\circ}$ parágrafo do artigo $1 .{ }^{\circ}$ e na segunda parte do $n .{ }^{\circ} 3$ do artigo $10 .{ }^{\circ}$ do TUE, ao exortarem à tomada de decisões de forma mais aberta e próxima dos cidadãos. Associado a essa democracia de proximidade vislumbra-se um pluralismo democrático assente na salvaguarda das identidades nacionais dos Estados membros ${ }^{59}$, prevista no n. ${ }^{\circ} 2$ do artigo $4 .^{\circ}$ do mesmo Tratado, objetivo igualmente prosseguido pela ideia de subsidiariedade.

\section{O reforço do papel dos Parlamentos nacionais na União Europeia}

A consolidação da democracia na UE também ocorreu através da associação dos Parlamentos nacionais aos domínios de intervenção daquela, aspeto decisivo na (i) redução do indesejado défice democrático na ação da União, no (ii) aumento da transparência da UE e das respetivas instituições, e na (iii) aproximação do projeto europeu aos cidadãos.

A participação dos Parlamentos no controlo político do respeito pelo princípio da subsidiariedade, igualmente decorrente do princípio do respeito das identidades nacionais, é confirmada no Protocolo anexo ao TUE, ao TFUE e ao TCEEA, relativo ao papel dos Par-

55 Assim Jacques DELORS, op. cit., pp. 170 e 171. O autor chama a atenção para um mau uso do princípio da subsidiariedade pelos Estados membros, visível num crescente esvaziamento da distinção entre estes dois atos, uma vez que ultimamente têm surgido diretivas que se assemelham a regulamentos já que o seu conteúdo se caracteriza pelo excesso de detalhe e pela ausência de concessão aos Estados de espaço de manobra na sua transposição.

56 Assim Ana Maria GUERRA MARTINS, O Tratado..., cit., p. 49.

57 Cfr. Direito..., cit., p. 366.

58 A expressão é de J. J. GOMES CANOTILHO, Direito..., cit., p. 366.

59 Cfr. FAUSTO DE QUADROS, Direito..., cit., p. 142. 
lamentos nacionais na UE, aprovado pela CIG que adotou o Tratado de Lisboa ${ }^{60}$ (artigo $\left.3 .^{\circ}\right)$. Nele, os Parlamentos nacionais são associados ao controlo da ação governamental em matéria europeia ${ }^{61}$ mediante a transmissão dos projetos de atos legislativos europeus ${ }^{62}$ (artigo $2^{\circ}{ }^{\circ}$ ). Prevê-se também o estabelecimento de uma cooperação interparlamentar entre o PE e os Parlamentos nacionais regular e eficaz ao nível da União (artigo 9. ${ }^{\circ}$ ), no âmbito da qual a Conferência dos Órgãos dos Parlamentos Nacionais especializados em Assuntos Europeus (COSAC) pode dirigir às instituições europeias participantes nos processos decisórios (Comissão, Conselho e $\mathrm{PE}$ ) contributos adequados sobre a atividade legislativa da União nos mais variados domínios (v. g. espaço de liberdade, segurança e justiça; direitos, liberdades e garantias individuais; direitos fundamentais em geral; etc.).

\section{Cidadania Europeia: o ser ou não ser de uma democracia participativa}

Outra dimensão do princípio democrático tem em vista a vertente de participação, que implica o exercício direto da cidadania e a mobilização dos cidadãos no produto final da decisão democrática, assim legitimando os próprios decisores ${ }^{63}$.

A prevalência da dimensão democrática representativa no desenvolvimento do funcionamento da UE, expressamente assumida no n. ${ }^{\circ} 1$ do artigo $10 .^{\circ}$ do TUE, é inequívoca. Ao longo da evolução do processo europeu de integração os Tratados preocuparam-se em consolidar a dimensão representativa do princípio democrático. Assim, aquele processo caracteriza-se, igualmente, por um défice no que tange aos instrumentos da dimensão participativa do mesmo princípio, constatando Boaventura de SOUSA SANTOS ${ }^{64}$ que os domínios da UE são um bom exemplo de uma área social que situada fora da intervenção participativa dos cidadãos em virtude de aí se verificar uma redução da política a uma prática social setorial e especializada e na rígida regulação da participação dos cidadãos nessa prática.

60 O qual substituiu o anterior Protocolo referente à mesma matéria, anexo ao TUE, ao TCE e ao TCEEA, adotado pela CIG que aprovou o Tratado de Amesterdão. Em ambos os Protocolos os Estados membros afirmaram a sua vontade em "incentivar uma maior participação dos Parlamentos nacionais nas actividades da União Europeia e reforçar a capacidade de exprimirem as suas opiniões sobre questões que para aqueles possam revestir especial interesse".

61 Cfr. FAUSTO DE QUADROS, Direito..., cit., p. 403; Ana Maria GUERRA MARTINS, Curso..., cit., p. 93.

62 Assemelhando-se a Comissão (autora da esmagadora maioria das propostas de atos legislativos europeus, bem como de alguns regulamentos de execução e regulamentos delegados) a um Executivo europeu, estamos diante de um instrumento de controlo político dos Parlamentos nacionais sobre tal Executivo, o que traduz um plus face ao controlo político que o PE exerce sobre a Comissão e sobre a ação dos respetivos Governos nacionais em matéria europeia, uma vez que no Conselho, composto por representantes dos Estados membros ao nível ministerial, reside a competência decisória.

63 Cfr. Fernando RUIVO, Cidadania activa, movimentos sociais e democracia participativa, in RCCS, n. ${ }^{\circ}$ 54, 1999 , p. 174.

64 Cfr. op. cit., p. 105 
Será, por isso, legítimo questionar onde paira, na UE, a democracia participativa?

No atual estádio da integração o mencionado défice não é sinónimo de total ausência dessa dimensão do princípio democrático. Dúvidas não se levantarão, porém, quanto ao facto de muito estar ainda por fazer. O direito de petição ao $\mathrm{PE}$ e o direito de queixa ao Provedor de Justiça Europeu, também integrantes do estatuto da cidadania da União, serão dois mecanismos precursores da dimensão participativa do princípio democrático em que a UE assenta. Acresce uma novidade introduzida pelo Tratado de Amesterdão: a faculdade de os cidadãos europeus se dirigirem, por escrito, às instituições da UE numa das línguas previstas no $n .{ }^{\circ} 1$ do artigo $55 .{ }^{\circ}$ do TUE e o direito de obterem do destinatário uma resposta, também por escrito, na mesma língua ( $4 .^{\circ}$ parágrafo do artigo $24 .^{\circ}$ do TUE).

Todavia, inexiste a figura do referendo europeu, expressão da democracia semidireta ${ }^{65} \mathrm{e}$ do envolvimento imediato dos cidadãos da UE, mediante consulta popular aos povos dos Estados membros sobre questões de relevante interesse europeu inseridas na esfera de atribuições da União, o que contribui para alguma neutralização da capacidade emancipatória do princípio democrático enquanto traço político marcante da $\mathrm{UE}^{66}$.

O Tratado de Lisboa deu importantes passos nesse caminho. O n. 3 do artigo $10 .^{\circ}$ do TUE introduz, prima facie, o direito de todos os cidadãos a "participar na vida democrática da União", aqui residindo um gérmen programático de mecanismos de democracia participativa no seio da UE; mais se acrescenta que "as decisões são tomadas de forma tão aberta e tão próxima dos cidadãos quanto possível". Eloquente é também o novo n. ${ }^{\circ} 4$ do artigo $11 .^{\circ}$ do TUE, ao prever o direito de os cidadãos convidarem a Comissão a apresentar propostas de atos de direito derivado ( $v . g$. de regulamentos e de diretivas) em matérias nas quais

65 Assim J. J. GOMES CANOTILHO, Direito..., cit., pp. 294 e ss.

66 Em 2004, na assinatura do Tratado que institui uma Constituição para a Europa, os Estados membros assumiram o compromisso assinalável de ratificar aquele Tratado por via referendária. Não se tratou de um referendo europeu, mas de vários referendos nacionais sobre uma questão comum. Entre nós, em 2005, a CRP foi inclusive objeto de uma revisão extraordinária que culminou com a introdução do novo artigo $295 .^{\circ}$, que prevê a convocação de referendos sobre a aprovação de tratados que visem a construção e o aprofundamento da UE. Todavia, a não aprovação da Constituição Europeia devido às rejeições referendárias francesa e holandesa encarregar-se-ia de refrear os ímpetos dos governantes dos Estados membros relativamente à utilização daquela via de ratificação de tratados internacionais. Prova disso foi a prevalência da forma parlamentar no processo de ratificação do Tratado de Lisboa (com exceção da Irlanda, cuja Constituição obriga à convocação do referendo para aprovação de tratados europeus). Paulo de PITTA E CUNHA, O Tratado de Lisboa. Génese, conteúdo e efeitos, Lisboa, 2008, p. 41, rotula todo este processo de volte-face relativamente à via ratificativa do Tratado de Lisboa de "habilidade", destacando ainda a passagem de um "atestado de menoridade politica passado aos cidadãos" pelos Estados membros, maxime naqueles onde já se realizaram referendos a tratados europeus. Muito embora exista idêntica legitimidade democrática nas duas formas de ratificação, tal alteração inculca duas constatações: o receio dos governantes dos Estados relativamente à incerteza dos mecanismos de aprovação dos Tratados que passem pela consulta dos respetivos povos; por outro lado, indiretamente, está ainda muito longínqua a figura jurídica do referendo europeu e, com ele, um passo decisivo para a implementação de um dos principais mecanismos de democracia participativa no seio da UE. 
considerem necessária a adoção dos $\operatorname{mesmos}^{67}$. Exige-se a participação de, pelo menos, um milhão de peticionantes, os quais devem ser cidadãos da UE e nacionais de um número significativo de Estados membros. Trata-se de um número elevado que poderá contribuir para que este mecanismo dificilmente venha a ser despoletado, o que contribui para uma rígida regulação da participação dos cidadãos no domínio político enquanto prática social setorial e especializada $a^{68}$, a que acresce uma potencial limitação à capacidade emancipatória do ideal democrático no seio da $U E^{69}$. Não se trata ainda de atribuir aos cidadãos europeus o direito, partilhado com a Comissão, de iniciativa legislativa. Todavia, um primeiro passo nesse sentido poderá ter sido dado. Encontramos aqui um mecanismo pioneiro que tem a dimensão participativa do princípio democrático no horizonte. Com ele também se vislumbra um novo dever em que as instituições europeias ficam investidas: recorrendo aos meios adequados, elas darão aos cidadãos e às associações representativas a possibilidade de expressarem e partilharem publicamente os seus pontos de vista sobre todos os domínios de ação da União (n. ${ }^{\circ} 1$ do artigo $11 .^{\circ}$ do TUE).

\section{Conclusão}

O respeito do princípio democrático é, desde logo, exigível aos Estados europeus que desejem aderir à UE; igualmente, eventuais violações do mesmo pelos Estados membros podem justificar a aplicação de sanções pela União. Contudo, não sendo a UE um Estado e inexistindo uma soberania popular europeia, o princípio democrático agiliza uma dialética relativamente ao funcionamento interno da própria União enquanto organização internacional e externo nas relações estabelecidas com os Estados membros e com os particulares (maxime cidadãos e empresas). O défice democrático denunciado recentemente pelo Presidente da Comissão Jean-Claude Juncker a propósito da intervenção da troika (composta pelo FMI, BCE e Comissão Europeia) em Portugal, na Grécia e na Irlanda, deve ser um exemplo a não repetir, principalmente numa altura em que a União se deve centrar em desafios que relancem o projeto europeu - assente na reconciliação, na democracia e nos direitos fundamentais - e não apenas nas políticas orçamentais dos Estados.

67 Cfr. FAUSTO DE QUADROS, Direito..., cit., p. 163; Jónatas MACHADO, Direito da União Europeia, Coimbra, 2010, p. 253.

68 Ver Boaventura de SOUSA SANTOS, op. cit., p. 105

69 Na síntese de Paulo de PITTA E CUNHA, op. cit., p. 54, "o tão falado direito de iniciativa dos cidadãos na elaboração da legislação europeia decorre de preceitos de muito duvidoso alcance prático". 